\title{
Effects of diabetes and treatment with the antioxidant $\alpha$-lipoic acid on endothelial and neurogenic responses of corpus cavernosum in rats
}

\author{
A. Keegan, M. A. Cotter, N.E. Cameron \\ Department of Biomedical Sciences, University of Aberdeen, Aberdeen, Scotland, UK
}

\begin{abstract}
Summary Diabetes mellitus is associated with impotence in animal models and patients. Raised reactive oxygen species contribute to diabetic neurovascular deficits, which are amenable to antioxidant treatment. Our aim was to examine the effects of streptozotocin-induced diabetes in rats and long-term treatment with the antioxidant, $\alpha$-lipoic acid, on responses of an in vitro corpus cavernosum preparation. Diabetes duration was 8 weeks and preventive and reversal (4 weeks untreated diabetes, 4 weeks of treatment) studies were done. Four and 8 weeks of diabetes caused an about $41 \%$ reduction in endothelium-dependent nitric oxide mediated relaxation to acetylcholine in phenylephrine-precontracted cavernosum. This deficit was prevented $(93.9 \pm 7.1 \%)$ by treatment with $\alpha$-lipoic acid; reversal studies showed $64.9 \pm 19.5 \%$ correction. Neither diabetes nor treatment with $\alpha$-lipoic acid altered endothelium-independent relaxation to the nitric oxide donor, sodium nitroprusside. Stimulation of corpus cavernosum autonomic innervation caused noradrenergic-mediated contractions that were unaffected by diabetes or $\alpha$-lipoic acid. Non-adrenergic, non-cholinergic nerve re-
\end{abstract}

sponses, largely dependent on nitric oxide, were seen after phenylephrine precontraction in the presence of atropine and guanethidine. Non-adrenergic, non-cholinergic stimulation caused frequency dependent relaxation to a maximum of about $40 \%$. Diabetes reduced this to about $25 \%$, however with preventive $\alpha$-lipoic acid treatment, non-adrenergic, noncholinergic relaxation was in the nondiabetic range. In the reversal $\alpha$-lipoic acid treated diabetic group, its deficit was corrected by $52.1 \pm 14.6 \%$. Thus, diabetes reduces endothelium and non-adrenergic, noncholinergic nerve nitric oxide-mediated relaxation of corpus cavernosum smooth muscle, which is likely to be the organic base for impotence. Prevention and partial correction by $\alpha$-lipoic acid emphasises the importance of reactive oxygen species and suggests a potential therapeutic approach. [Diabetologia (1999) 42: 343-350]

Keywords Diabetes mellitus, corpus cavernosum, autonomic neuropathy, antioxidant, nitric oxide, impotence, rat.
Received: 27 July 1998 and in revised form: 25 September 1998

Corresponding author: Dr. N. E. Cameron, Department of Biomedical Sciences, Institute of Medical Sciences, Aberdeen University, Foresterhill, Aberdeen AB25 2ZD, Scotland, UK Abbreviations: ACh, Acetylcholine; AGE, advanced glycation end product; GSH, reduced glutathione; LA, $\alpha$-lipoic acid; NO, nitric oxide; NOS, nitric oxide synthase; NANC, non-adrenergic non-cholinergic; ROS, reactive oxygen species; SNP, sodium nitroprusside; TEFS, transmural electrical field stimulation; VIP, vasoactive intestinal polypeptide.
Males with diabetes mellitus have an increased prevalence of erectile dysfunction. Some of the organic causes have been studied in corpus cavernosum strips isolated from men undergoing penile prosthesis implantation. Defects in endothelium-dependent and nerve-mediated vascular smooth muscle relaxation have been found [1]. Similar deficits were noted for alloxan-diabetic rabbits [2] and recently diminished neurogenic erections were reported in streptozotocin-diabetic rats [3]. The nitric oxide (NO) systems of corpus cavernosum endothelium and nerve supply are crucial for smooth muscle relaxation and erectile 
function $[4,5]$ and in some diabetic rat models cavernosal NO synthase (NOS) is diminished [6].

Impaired NO-mediated vasodilation is commonly found in vivo and in vitro for individual vessels and vascular beds of diabetic animal models [7-17] and has been noted in several studies on patients [18-21]. One potential cause is the raised level of reactive oxygen species (ROS) in diabetes [22], which could react with NO to neutralise its vasodilator activity [23]. Defects in endothelium-dependent relaxation of large and small vessels could be prevented by antioxidant treatment in diabetic rats [9-12], although there has been a recent dissenting report for mesenteric vessels [24]. $\alpha$-Lipoic acid (LA) is a powerful antioxidant, possessing both radical scavenger and transition metal chelator properties [25], that has recently been shown to improve nerve blood flow, glutathione (GSH) content and motor and sensory conduction velocity in diabetic rats $[26,27]$. The aims of this investigation were to assess the effects of diabetes and long-term LA treatment on endothelial and neurogenic function using an in vitro rat corpus cavernosum preparation [28].

\section{Materials and methods}

Male Sprague-Dawley rats (Aberdeen University colony) were used, aged 19 weeks at the start of experiments. Diabetes was induced by intraperitoneal injection of streptozotocin (Zeneca, Macclesfield, Cheshire, UK) freshly made up in sterile $154 \mathrm{mmol} \cdot \mathrm{l}^{-1} \mathrm{NaCl}$ solution, at a dose of $40-45 \mathrm{mg} \cdot \mathrm{kg}^{-1}$. Diabetes was verified after $24 \mathrm{~h}$ by the presence of hyperglycaemia and glucosuria (Visidex II and Diastix; Ames, Slough, UK) in non-fasted rats. After that, rats were tested weekly, and weighed daily; they were rejected if blood glucose was $<20 \mathrm{mmol} \cdot \mathrm{l}^{-1}$ or if they showed a consistent increase in body weight over 3 days.

After final experiments, plasma glucose was estimated (GOD-Perid method; Boehringer Mannheim, Mannheim, Germany) on samples taken from the tail vein. Diabetes duration was 8 weeks and two studies, prevention and reversal, were undertaken. In the preventive study, one group acted as diabetic controls and another group was treated with LA as a dietary supplement (dose $300 \mathrm{mg} \cdot \mathrm{kg}^{-1} \cdot$ day $^{-1}$ racemate; ASTA Medica AWD, Frankfurt, Germany). Treatment was started within 2 days of streptozotocin injection once the hyperglycaemic state was confirmed. Onset and age-matched groups were used as untreated nondiabetic controls and a further group of nondiabetic rats was given LA treatment (300 $\mathrm{mg} \cdot \mathrm{kg}^{-1} \cdot$ day $^{-1}$ racemate). In the reversal study, groups comprised onset nondiabetic controls, 4-week and 8-week diabetic controls and a group of diabetic rats untreated for the first 4 weeks and then given LA treatment (300 $\mathrm{mg} \cdot \mathrm{kg}^{-1} \cdot$ day $^{-1}$ racemate) for the last 4 weeks.

In final experiments, rats were anaesthetised $(4 \%$ halothane in air), the penis was excised at its base and the shaft was dissected free of connective and adventitial tissue. The copora cavernosa were separated, a longitudinal slit was made in each cavernosum to aid drug penetration and they were mounted separately in organ baths. Cavernosa were bathed in modified Krebs-Ringers solution $\left(144.0 \mathrm{Na}^{+}, 5.0 \mathrm{~K}^{+}, 1.25\right.$ $\mathrm{Ca}^{2+}, 1.1 \mathrm{Mg}^{2+}, 25.0 \mathrm{HCO}_{3}^{-}, 1.1 \mathrm{PO}_{4}^{3-}, 1.1 \mathrm{SO}_{4}^{2-}, 5.5$ glucose; in $\mathrm{mmol} \cdot \mathrm{l}^{-1}$ ) at $37^{\circ} \mathrm{C}$ and gassed continuously with $95 \%$ $\mathrm{O}_{2}: 5 \% \mathrm{CO}_{2}(\mathrm{pH} 7.35)$. Tension was monitored by isometric transducers and resting tension was set at $1.5 \mathrm{~g}$, which was established in pilot experiments as optimal for tension production when cavernosa were stimulated by phenylephrine [28]. Tissues were equilibrated for $60 \mathrm{~min}$, then they were precontracted with phenylephrine at a dose $\left(30 \mu \mathrm{mol} \cdot \mathrm{l}^{-1}\right)$ giving about $60 \%$ of the maximum contraction in all groups [28]. Cumulative concentration-response relations were determined for endothelium-dependent relaxation to acetylcholine (ACh) and endothelium-independent relaxation to sodium nitroprusside.

Repetitive supramaximum transmural electrical field stimulation (TEFS) of autonomic nerves was accomplished via platinum wire electrodes placed either side of the cavernosum (duration $15 \mathrm{~s}$; amplitude 50-90 V; frequency range 2-20 Hz; pulse width $5 \mathrm{~ms}$ ). Frequency-response curves were determined for noradrenergic vasoconstrictor nerves. Preparations were then preincubated for $30 \mathrm{~min}$ with guanethidine $\left(5 \mu \mathrm{mol} \cdot \mathrm{l}^{-1}\right)$ to eliminate responses mediated by noradrenergic nerves, and atropine $\left(1 \mu \mathrm{mol} \cdot \mathrm{l}^{-1}\right)$ to prevent cholinergic nerve responses. After phenylephrine $\left(30 \mu \mathrm{mol} \cdot \mathrm{1}^{-1}\right)$ precontraction under these conditions, TEFS showed relaxation mediated by non-adrenergic, non-cholinergic (NANC) fibres. In preliminary experiments on cavernosa from nondiabetic $(n=4)$, diabetic $(n=4)$ and prevention LA-treated diabetic $(n=4)$ rats, the specificity of responses to neural stimulation was tested by preincubation with tetrodotoxin $\left(1 \mu \mathrm{mol} \cdot \mathrm{l}^{-1}\right)$ for $30 \mathrm{~min}$.

Statistical analysis. Data are expressed as means \pm SEM. They were subjected to Bartlett's test for homogeneity of variances and where necessary they were normalised by log transformation before being tested using one-way analysis of variance. When significance was attained $(p<0.05)$, between-group differences were established using the Student-Newman-Keuls multiple comparison test. Concentration-response curves were fitted by sigmoid curves using the least squares method to estimate $\mathrm{EC}_{50}$. Calculations were made using a standard statistical software package (Prism, Graphpad, San Diego, Calif., USA).

\section{Results}

Diabetic groups had an approximate fourfold increase of plasma glucose concentration (Table 1), which was not significantly altered by LA treatment in prevention or reversal groups. This treatment also did not affect plasma glucose in nondiabetic rats compared with onset or age-matched controls. Diabetic rats showed about $30 \%$ weight loss over the experimental period, which was not significantly affected by LA treatment. In contrast, nondiabetic rats increased their weight by about $7 \%$ over the 8 -week experimental period, except for the LA-treated nondiabetic group, where there was a small weight loss $(6.2 \% ; p<0.001$, paired Student's $t$-test $)$.

Preventive study. Endothelium dependent relaxation (Fig. 1) to ACh was impaired by diabetes $(p<0.001)$, maximum relaxation being $29.4 \pm 3.0 \%$ compared to onset $(51.2 \pm 2.5 \%)$ or age-matched $(47.0 \pm 1.5 \%)$ 
Table 1. Body weights and plasma glucose concentrations for rat groups in prevention and reversal studies

\begin{tabular}{|c|c|c|c|c|}
\hline \multirow[t]{2}{*}{ Group } & \multirow[t]{2}{*}{$n$} & \multicolumn{2}{|c|}{ Body weight (g) } & \multirow{2}{*}{$\begin{array}{l}\text { Plasma } \\
\text { glucose } \\
\left(\mathrm{mmol} \cdot \mathrm{l}^{-1}\right)\end{array}$} \\
\hline & & Start & End & \\
\hline \multicolumn{5}{|l|}{ Nondiabetic } \\
\hline Onset control & 30 & $427 \pm 4$ & - & $10.1 \pm 0.6$ \\
\hline Age-matched control & 9 & $419 \pm 5$ & $451 \pm 6$ & $9.5 \pm 0.8$ \\
\hline$\alpha$-Lipoic acid treatment & 9 & $437 \pm 4$ & $410 \pm 4$ & $11.8 \pm 1.2$ \\
\hline \multicolumn{5}{|l|}{ Diabetic } \\
\hline 4 weeks & 11 & $451 \pm 10$ & $345 \pm 9$ & $43.8 \pm 1.3$ \\
\hline 8 weeks & 27 & $449 \pm 4$ & $293 \pm 5$ & $43.8 \pm 1.3$ \\
\hline \multirow{3}{*}{$\begin{array}{l}\alpha \text {-Lipoic acid prevention } \\
\text { treatment } \\
\alpha \text {-Lipoic acid reversal } \\
\text { treatment }\end{array}$} & & & & \\
\hline & 15 & $450 \pm 7$ & $301 \pm 6$ & $39.0 \pm 2.7$ \\
\hline & 11 & $444 \pm 5$ & $302 \pm 5$ & $41.7 \pm 3.1$ \\
\hline
\end{tabular}

Data are means \pm SEM

Table 2. Effects of 4 -h preincubation in 5.5 or $40 \mathrm{mmol} \cdot \mathrm{l}^{-1}$ glucose on relaxation to acetylcholine of phenylephrine-precontracted corpus cavernosa from nondiabetic and diabetic rats

\begin{tabular}{lcccc}
\hline Group & $n$ & $\begin{array}{l}\text { Precontrac- } \\
\text { tion tension } \\
(\mathrm{g} \cdot \mathrm{g} \text { wet } \\
\left.\mathrm{wt}^{-1}\right)\end{array}$ & $\begin{array}{l}\text { Maximum } \\
\text { relaxation } \\
(\%)\end{array}$ & $\begin{array}{l}(-\mathrm{log}) \mathrm{EC}_{50} \\
\left(\mathrm{~mol} \cdot \mathrm{l}^{-1}\right)\end{array}$ \\
\hline $\begin{array}{l}\text { Nondiabetic } \\
5.5 \mathrm{mmol} \cdot \mathrm{l}^{-1} \text { glucose }\end{array}$ & 8 & $2.28 \pm 0.42$ & $46.2 \pm 2.6$ & $5.76 \pm 0.21$ \\
$40 \mathrm{mmol} \cdot \mathrm{l}^{-1}$ glucose & $2.62 \pm 0.48$ & $43.3 \pm 1.8$ & $5.81 \pm 0.14$ \\
8 week diabetic & 6 & & & \\
$5.5 \mathrm{mmol} \cdot \mathrm{l}^{-1}$ glucose & $2.39 \pm 0.25$ & $24.5 \pm 2.9^{\mathrm{a}}$ & $6.00 \pm 0.17$ \\
$40 \mathrm{mmol} \cdot \mathrm{l}^{-1}$ glucose & $2.51 \pm 0.41$ & $26.1 \pm 2.9^{\mathrm{a}}$ & $5.81 \pm 0.14$
\end{tabular}

Data are means \pm SEM. ${ }^{a} p<0.001$ vs nondiabetic group exposed to the same glucose concentration

Table 3. Effects of diabetes and $\alpha$-lipoic acid treatment on corpus cavernosum relaxation to sodium nitroprusside

\begin{tabular}{llll}
\hline Group & $n$ & $\begin{array}{l}\text { Maximum } \\
\text { relaxation } \\
(\%)\end{array}$ & $\begin{array}{l}(-\log ) \mathrm{EC}_{50} \\
\left(\mathrm{~mol} \cdot \mathrm{l}^{-1}\right)\end{array}$ \\
\hline Nondiabetic control & 9 & $48.8 \pm 2.5$ & $5.88 \pm 0.17$ \\
Nondiabetic $+\alpha$-lipoic acid & 9 & $50.9 \pm 4.1$ & $5.76 \pm 0.14$ \\
Diabetic control & 9 & $47.6 \pm 3.4$ & $5.76 \pm 0.20$ \\
Diabetic $+\alpha$-lipoic acid & 9 & $47.7 \pm 2.5$ & $6.24 \pm 0.19$ \\
\hline
\end{tabular}

Data are means \pm SEM

control values. Treatment with LA did not alter maximum relaxation $(51.5 \pm 2.9 \%)$ in nondiabetic rats. In strong contrast, maximum relaxation was in the nondiabetic range $(47.9 \pm 1.4 \%)$ for LA-treated diabetic rats $(p<0.001$ vs diabetic control group). Neither diabetes nor LA treatment altered sensitivity to ACh; $(-\log ) \mathrm{EC}_{50}$ values were $5.86 \pm 0.13, \quad 5.74 \pm 0.10$, $5.65 \pm 0.20,5.69 \pm 0.12$ and $5.77 \pm 0.10$ for onset and age-matched control, LA-treated nondiabetic, diabetic control and LA-treated diabetic groups, respectively.

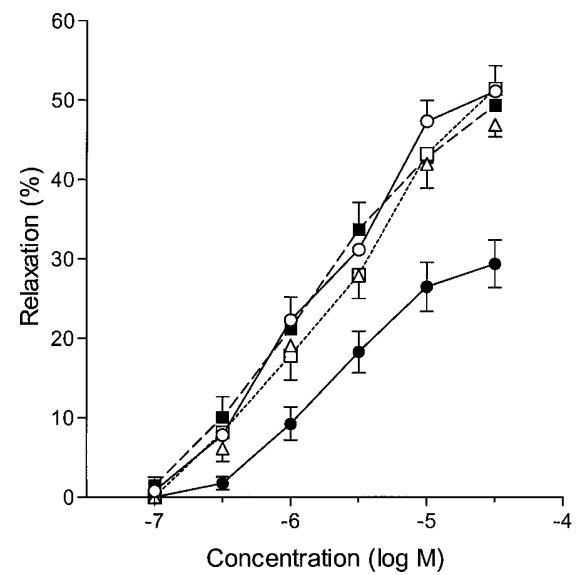

Fig. 1. Concentration-response curves for relaxation to acetylcholine after phenylephrine precontraction of corpus cavernosa from nondiabetic and diabetic rats in vitro and the effects of chronic preventive $\alpha$-lipoic acid treatment. Groups: nondiabetic onset control $(\bigcirc$, solid line, $n=14)$; nondiabetic agematched control $(\Delta, n=9)$; nondiabetic group treated with $300 \mathrm{mg} \cdot \mathrm{kg}^{-1} \cdot$ day $^{-1} \alpha$-lipoic acid for 8 weeks $(\square$, fine dashed line, $n=9$ ); 8 -week diabetic control $(\mathbf{O}$, solid line, $n=14)$; 8 -week diabetic rats treated from induction with $300 \mathrm{mg} \cdot \mathrm{kg}^{-1} \cdot$ day $^{-1} \alpha$-lipoic acid ( $\boldsymbol{\square}$, coarse dashed line, $n=15$ ). Data are means \pm SEM. Statistics: $p<0.05$, diabetic control group vs onset control and lipoic acid treated diabetic groups for acetylcholine concentrations $\geq 1 \mu \mathrm{mol} \cdot \mathrm{l}^{-1}$

The reduced responses to ACh could not be mimicked in corpus cavernosa from nondiabetic rats perifused with a solution high in glucose. Thus, paired experiments (Table 2) were carried out in which one cavernosum from a rat was preincubated for $4 \mathrm{~h}$ in $5.5 \mathrm{mmol} \cdot \mathrm{l}^{-1}$ glucose and the other one was exposed to $40 \mathrm{mmol} \cdot \mathrm{l}^{-1}$ glucose for the same time period. There were no significant differences in the tension generated in response to the $30 \mu \mathrm{mol} \cdot \mathrm{l}^{-1}$ phenylephrine precontracting stimulus and there were no significant changes in maximum relaxation or $(-\log ) \mathrm{EC}_{50}$ to ACh. Moreover, the diabetic deficit in ACh relaxation was unaffected by ambient glucose concentration at the time of measurement (Table 1). Acetylcholine-induced relaxation responses at $5.5 \mathrm{mmol} \cdot \mathrm{l}^{-1}$ glucose were unaffected by preincubation with the cyclooxygenase inhibitor, flurbiprofen $\left(10 \mu \mathrm{mol} \cdot \mathrm{l}^{-1}\right)$ but were completely abolished by NOS inhibition with $10 \mu \mathrm{mol} \cdot 1^{-1} \quad N^{\mathrm{G}}$-nitro-L-arginine (data not shown).

In contrast to the findings for acetylcholine, endothelium-independent relaxation to sodium nitroprusside (SNP) in phenylephrine-precontracted corpora cavernosa was unaffected by diabetes or LA treatment for maximum relaxation or $(-\log ) \mathrm{EC}_{50}$ (Table 3).

Transmural electrical field stimulation of corpus cavernosum caused frequency-dependent contractions (Fig. 2) that were completely blocked by guanethidine $\left(5 \mu \mathrm{mol} \cdot \mathrm{l}^{-1}\right)$ or tetrodotoxin 


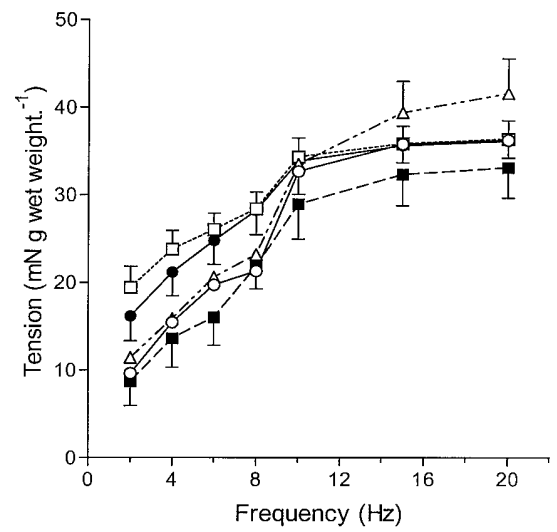

Fig. 2. Frequency-response curves for tension production in response to transmural electrical field stimulation of corpus cavernosa from nondiabetic and diabetic rats and the effects of long-term preventative $\alpha$-lipoic acid treatment. Groups: nondiabetic onset control ( $\bigcirc$, solid line, $n=15)$; nondiabetic age-matched control ( $\Delta$, dot-dashed line, $n=9)$; nondiabetic group treated with $300 \mathrm{mg} \cdot \mathrm{kg}^{-1} \cdot \mathrm{day}^{-1} \alpha$-lipoic acid for 8 weeks ( $\square$, fine dashed line, $n=9$ ); 8-week diabetic control $(\bigcirc$, solid line, $n=15)$; 8 -week diabetic rats treated from induction with $300 \mathrm{mg} \cdot \mathrm{kg}^{-1} \cdot \mathrm{day}^{-1} \alpha$-lipoic acid $(\boldsymbol{\square}$, coarse dashed line, $n=15)$. There were no statistically significant betweengroup differences at any stimulation frequency

$\left(1 \mu \mathrm{mol} \cdot \mathrm{l}^{-1}\right)$. When expressed in terms of tension production per tissue weight, contractions were not significantly altered by diabetes or LA treatment. For cavernosa precontracted with phenylephrine, in the presence of guanethidine to block the noradrenergic contractile responses, and $N^{\mathrm{G}}$-nitro-L-arginine $\left(10 \mu \mathrm{mol} \cdot \mathrm{l}^{-1}\right)$ to block nitrergic relaxation responses, a minor relaxation to TEFS was observed in nondiabetic tissues (maximum at $20 \mathrm{~Hz} ; 7.8 \pm 1.3 \%, n=6$ ). This was unaffected by 8 weeks of diabetes $(7.9 \pm 1.5 \%, n=6)$ and was abolished by atropine $\left(1 \mu \mathrm{mol} \cdot \mathrm{l}^{-1}\right)$, suggesting that this relaxation was derived from cholinergic muscarinic fibres.

Transmural electrical field stimulation in phenylephrine precontracted cavernosa, pretreated with both guanethidine and atropine, gave frequency-dependent relaxation that was completely abolished by $N^{\mathrm{G}}$-nitro-L-arginine $\left(10 \mu \mathrm{mol} \cdot \mathrm{l}^{-1}\right)$ or tetrodotoxin $\left(1 \mu \mathrm{mol} \cdot \mathrm{l}^{-1}\right)$. This NANC relaxation (Fig. 3$)$ reached a maximum of $40.0 \pm 1.5 \%$ and $40.1 \pm 2.4 \%$ in onset and age-matched control groups, respectively. Diabetes blunted the response by $38 \%$ to $24.7 \pm 1.5 \%$ $(p<0.001)$. Treatment with LA did not significantly affect NANC relaxation in cavernosa from nondiabetic rats $(45.5 \pm 3.9 \%)$, however, in diabetic rats, relaxation $(42.6 \pm 2.6 \%)$ was in the nondiabetic range, greater $(p<0.001)$ than for the diabetic control group.

The NANC responses were not significantly influenced by short-term exposure to glucose. In paired experiments where one cavernosum from a rat was preincubated for $4 \mathrm{~h}$ in $5.5 \mathrm{mmol} \cdot \mathrm{l}^{-1}$ glucose

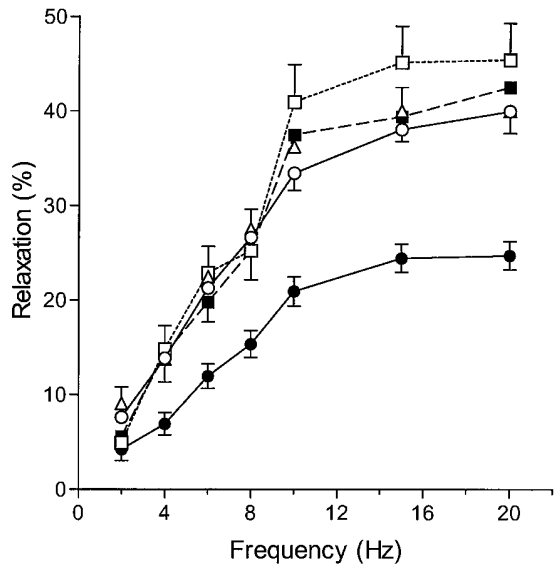

Fig.3. Frequency-response curves for relaxation in response to transmural electrical field stimulation of corpus cavernosa from nondiabetic and diabetic rats in the presence of guanethidine and atropine, and the effects of long-term preventative $\alpha$ lipoic acid treatment. Groups: nondiabetic onset control $(\bigcirc$, solid line, $n=18)$; nondiabetic age-matched control $(\Delta$, dotdashed line, $n=9)$; nondiabetic group treated with $300 \mathrm{mg} \cdot \mathrm{kg}^{-1} \cdot$ day $^{-1} \alpha$-lipoic acid for 8 weeks $(\square$, fine dashed line, $n=10)$; 8 week diabetic control (, solid line, $n=18) ; 8$ week diabetic rats treated from induction with $300 \mathrm{mg} \cdot \mathrm{kg}^{-1} \cdot$ day $^{-1} \alpha$-lipoic acid ( $\boldsymbol{\square}$, coarse dashed line, $n=18)$. Data are means \pm SEM. Statistics: $p<0.05$, diabetic control group vs all other groups at $6-20 \mathrm{~Hz}$

and the other one was exposed to $40 \mathrm{mmol} \cdot \mathrm{l}^{-1}$ glucose for the same period, maximum relaxation at $20 \mathrm{~Hz}$ in nondiabetic rats $(n=6)$ was $37.4 \pm 2.3 \%$ at $5.5 \mathrm{mmol} \cdot \mathrm{l}^{-1}$ glucose and $35.0 \pm 3.4 \%$ at $40 \mathrm{mmol} \cdot \mathrm{l}^{-1}$ glucose. In tissues from diabetic rats $(n=5)$, maximum relaxation was $27.2 \pm 2.8 \%$ at $5.5 \mathrm{mmol} \cdot \mathrm{l}^{-1}$ and $28.5 \pm 2.6 \%$ at $40 \mathrm{mmol} \cdot \mathrm{l}^{-1}$.

Reversal study. Relaxation to ACh in phenylephrineprecontracted corpus cavernosa is shown in Figure 4. Compared with maximum relaxation for nondiabetic onset controls $(48.9 \pm 2.1 \%)$, there were about $40 \%$ deficits with diabetes of $4(28.4 \pm 4.9 \% ; p<0.01)$ or $8(29.8 \pm 2.9 \% ; p<0.001)$ weeks duration. Treating diabetic rats with LA during the last 4 weeks caused an about $65 \%$ reversal of the diabetic deficit such that maximum relaxation $(41.7 \pm 4.0 \%)$ was improved compared with $4(p<0.05)$ and $8(p<0.05)$ week diabetic groups and was in the lower half of the nondiabetic range. There were no significant between-group differences in $\mathrm{ACh}(-\log ) \mathrm{EC}_{50}$ values which were $5.64 \pm 0.15,5.49 \pm 0.12,5.66 \pm 0.13$ and $5.71 \pm 0.09$ for onset control, 4 - and 8-week diabetic control and reversal LA treated diabetic groups respectively. There were no significant between-group differences in endothelium-independent relaxation to $\mathrm{SNP}$ for maximum relaxation or $(-\log ) \mathrm{EC}_{50}$ (data not shown).

The NANC responses to TEFS in phenylephrineprecontracted cavernosa preincubated with guanethi- 


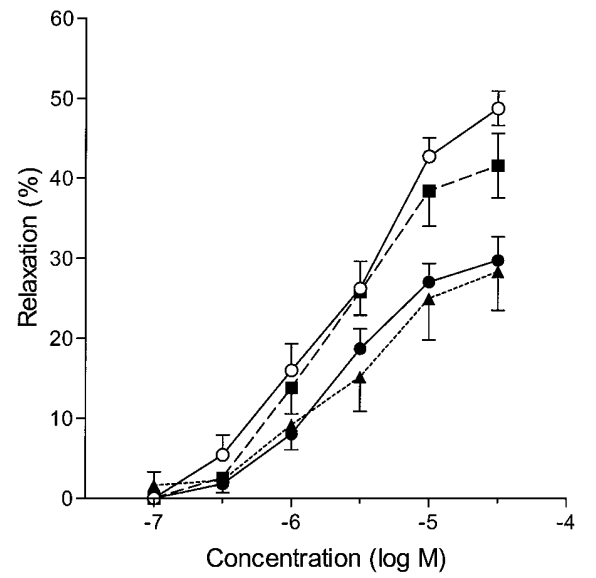

Fig.4. Concentration-response curves for relaxation to acetylcholine following phenylephrine precontraction of corpus cavernosa from nondiabetic and diabetic rats and the effects of chronic reversal $\alpha$-lipoic acid treatment. Groups: nondiabetic onset control $(\bigcirc$, solid line, $n=12)$; 4-week diabetic control $(\boldsymbol{\Delta}$, fine dashed line, $n=9)$; 8 -week diabetic control $(\mathbf{O}$, solid line, $n=12)$; 8 -week diabetic group untreated for 4 weeks and then treated with $300 \mathrm{mg} \cdot \mathrm{kg}^{-1}$. day ${ }^{-1} \alpha$-lipoic acid for the last 4 weeks $(\square$, coarse dashed line, $n=11)$. Data are means \pm SEM. Statistics: $p<0.05,4$ - and 8-week diabetic control groups vs all other groups for acetylcholine concentrations $\geq 10 \mu \mathrm{mol}$ $1^{-1}$

dine and atropine were similarly attenuated by 4 and 8 weeks of diabetes (Fig.5). Thus, maximum relaxation at $20 \mathrm{~Hz}$ was reduced from $39.6 \pm 2.2 \%$ in cavernosa from onset controls to $25.2 \pm 1.9 \%$ $(p<0.001)$ after 4 and $26.4 \pm 1.7 \%(p<0.001)$ after 8 weeks of diabetes. Treating diabetic rats with LA during the second 4 week period caused about $52 \%$ correction of the deficit such that maximum NANC relaxation was $32.7 \pm 2.1 \%$, which was greater $(p<0.05)$ than 4 - or 8 -week diabetic controls, although an impairment remained $(p<0.05)$ compared with the control group.

\section{Discussion}

Diabetes caused deficits in endothelium-dependent and NANC nerve-mediated relaxation of corpus cavernosum smooth muscle, independent of the ambient glucose concentration during measurements. This agrees with previous reports in rat, rabbit and man [1-3]. Nitric oxide is the major vasodilator released by corpus cavernosum endothelium and a diabetic deficit in synthesis, release or action, is in line with many observations including those from in vitro studies on large arteries [7-9, 11, 12], small muscle arteries [15], heart and mesenteric vascular beds [10, 29] and in vivo studies on sciatic vasa nervorum $[16,17]$, brain $[14,30]$ and skin [21]. In the majority of these tissues, relaxation to NO donors, such as sodium nitroprusside or glyceryl trinitrate, was not affected by

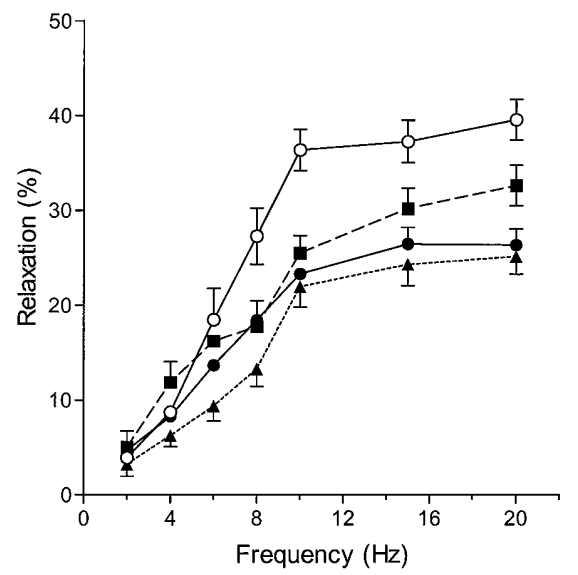

Fig. 5. Frequency-response curves for relaxation in response to transmural electrical field stimulation of corpus cavernosa from nondiabetic and diabetic rats and the effects of longterm reversal $\alpha$-lipoic acid treatment. Groups: nondiabetic onset control $(\bigcirc$, solid line, $n=10)$; 4-week diabetic control $(\boldsymbol{\Delta}$, fine dashed line, $n=11)$; 8 -week diabetic control $(\mathbf{O}$, solid line, $n=10$ ); 8 -week diabetic group untreated for 4 weeks and then treated with $300 \mathrm{mg} \cdot \mathrm{kg}^{-1} \cdot$ day $^{-1} \alpha$-lipoic acid for the last 4 weeks $(\square$, coarse dashed line, $n=10)$. Data are means \pm SEM. Statistics: $p<0.05$, nondiabetic onset control group vs 4 week diabetic group 6-20 Hz, and 8-week diabetic group and $\alpha$-lipoic acid treated diabetic group 8-20 Hz.; $\alpha$-lipoic acid treated diabetic group vs 4-week diabetic group 15-20 Hz and 8 -week diabetic group $20 \mathrm{~Hz}$

diabetes, as observed in this study for corpus cavernosum. In terms of an explanation for the ACh stimulated deficit, this rules out a defect in the cGMP mechanism and smooth muscle responsiveness to NO. Several possibilities remain which cannot be ruled out by our experimental findings, including abnormalities of ACh receptors or transduction mechanisms, reduced NO synthesis, and increased NO destruction.

A selective impairment of ACh transduction has been postulated for mesenteric vessels [31], however, at best this could only partially explain the corpus cavernosum data and is unlikely to apply more generally. Thus, NANC nerve relaxation, impaired by diabetes, is NO-mediated but ACh is not involved. Furthermore, in aorta, defective NO-mediated endothelium-dependent relaxation was noted when receptortransduction systems were bypassed using a calcium ionophore [32].

Diminished NO synthesis could result from a reduction in NOS content or activity, or substrate depletion. The latter is unlikely since, like aorta, corpus cavernosum remains responsive to ACh over several serial cumulative dose-response determinations without decrement [11]. Furthermore, there is a greater dietary intake of $\mathrm{L}$-arginine in diabetic rats and L-arginine transport is enhanced by diabetes/hyperglycaemia in human umbilical vein endothelial cells from women with gestational diabetes [33] although it is not known whether this effect is applicable to 
other endothelial cells or chronic diabetes in rats. Reduced penis total (endothelial and neuronal) NOS activity and neuronal NOS levels have been reported after 4-8 months in BB/WOR and BBZ/WPR rat models of Type I (insulin-dependent) and Type II (non-insulin-dependent) diabetes mellitus [6]. In streptozotocin-diabetic rats of 2-3 months duration, increased penile endothelial and total NOS, however, was found using autoradiographic and biochemical and assays [34, 35]. It is possible that changes in NOS activity are biphasic in diabetic rats, an initial increase being followed by a decline. For the 4- and 8 -week streptozotocin-diabetes durations used in this study, however, the literature suggests that at least endothelial NOS would be increased; therefore NOS changes would not explain the diminished relaxation to $\mathrm{ACh}$, which was similar at both time points. It is possible that in the intact tissue other factors alter NOS responses. For example, advanced glycation and increased protein kinase $\mathrm{C}$ activation can reduce NOS activity [36-38]. Long-, but not shortterm, treatment with aminoguanidine, which inhibits advanced glycation, prevents and reverses the endothelial NO defects that lead to reduced ACh responses and impaired tissue blood flow in diabetic rats [11, 13,39 ]. Furthermore, protein kinase $\mathrm{C}$ inhibitors improve blood flow in retina and nerve, which depends on a NO mechanism [40, 41].

Even if corpus cavernosum NOS activity were normal in diabetic rats, by neutralising NO, the increased ROS in diabetes would reduce ACh-stimulated relaxation. Therefore, the prediction on this hypothesis is that ROS scavengers would improve endotheliumdependent relaxation. The antioxidant, LA, provided a high level of protection and partially reversed an established defect. This is the first report of successful treatment of impaired corpus cavernosum endothelial responses in experimental diabetes. Like vitamin $\mathrm{E}, \mathrm{LA}$ is a scavenger however, it is a transition metal chelator, therefore it inhibits important sources of ROS formation in diabetes by metal catalysed processes including the Fenton reaction and advanced glycation [42]. This results in LA being about ten times more potent than vitamin $E$ against vascular deficits in diabetic rats $[27,43]$. The data are in general agreement with the literature on protective effects of scavenger and metal chelator treatment on endothelium dependent relaxation of blood vessels [9-12]. The observation that vitamin E does not preserve mesenteric vessel responses in diabetes is at odds with this conclusion, however, concomitant vitamin E exposure protected aorta, coronary circulation and vasa nervorum $[9,10,43]$, which argues against the generality of that finding. Furthermore, mesenteric responses are protected by LA [44], showing that they are amenable to potent antioxidant treatment.

The finding that LA only partially reversed an existing endothelial deficit suggests that defective NO- mediated relaxation is not only caused by ROS neutralisation of NO, otherwise complete reversal would be expected. In other tissues, for example in aorta and mesenteric vessels, reversal of defective AChmediated relaxation by short-term exposure to antioxidants has been reported $[45,46]$. In other experiments, short-term antioxidant treatment was, however, without effect on the diabetic deficit $[11,47]$. This suggests that as well as a ROS neutralisation of NO, there are less readily reversible diabetic changes. Candidates include endothelial damage, a build-up of advanced glycation end products (AGEs) which can quench NO [13], the reaction between superoxide and NO produces peroxynitrite which can nitrosylate proteins and also decays to form nitrogen dioxide and the highly reactive hydroxyl radical [48], and changes in gene expression. The antioxidant LA has a number of beneficial actions to combat these changes in diabetes. Thus, LA scavenges ROS, prevents lipid peroxidation, improves tissue GSH content, attenuates the activation of nuclear factor $\kappa B$ when AGEs bind to their receptors, and protects against peroxynitrite-induced nitrosylation of tyrosine residues in proteins $[25,26,49,50]$. There is no expectation that, once stimulated by diabetes, AGE formation, nitrosylation and changes in endothelial phenotypic expression mediated by nuclear factor $\mathrm{\kappa B}$, would be affected by LA treatment, therefore these factors could account for the poorly reversible component of the corpus cavernosum relaxation deficit.

The changes in corpus cavernosum autonomic control were specific; diabetes had a marked and early (4 weeks) effect on NANC fibres while sparing the noradrenergic innervation over the 8 -week study period. It could be that a greater duration of diabetes would eventually lead to noradrenergic dysfunction; in the mesenteric vascular bed vasodilator nerve function is impaired earlier than the vasoconstrictor innervation [29]. The major neurotransmitter in corpus cavernosum NANC nerves is $\mathrm{NO}$ and diabetic effects on the nitrergic NANC system appear to be generalised, similar relaxation defects being reported for anococcygeus muscle, stomach and duodenum [51-53]. Treatment with LA completely prevented and partially reversed the corpus cavernosum nitrergic nerve deficit, in line with its effects on the endothelium NO system. This is the first report of successful treatment of a diabetic nitrergic deficit. It is likely that mechanisms causing nitrergic nerve dysfunction are similar to those suggested for the endothelium and that a superoxide, NO, peroxynitrite mechanism could be involved. Thus, NANC relaxation could possibly be abolished in vitro in the presence of a free radical generating system provided superoxide dismutase is inhibited [54].

Vasoactive intestinal polypeptide (VIP) is co-localised with NOS in neurones innervating corpus cavernosum smooth muscle [55] and it could potentially 
have a role in NANC neurotransmission. Decreased sensitivity to exogenous VIP has been noted in diabetic rats [56], however, the relative importance of VIP is questionable. Intracavernosal injection does not produce a full erection in rats [57]. The effects of VIP are mediated by the cAMP system whereas in rat tissue and human cavernosum strips, NANC responses are blocked by NOS or guanylate cyclase inhibitors [58].

The diabetic deficits in corpus cavernosum ACh and NANC stimulated relaxations were not reproduced by acute exposure of nondiabetic tissue to high glucose concentrations. This has not previously been reported. In some other vascular tissues, effects to short-term glucose exposure are similar to those of diabetes. Thus, in rabbit and guinea pig aorta, high glucose effects are linked to ROS-stimulated endothelial release of a prostanoid vasoconstrictor which opposes ACh-induced relaxation [59, 60]. A similar effect was noted for rat mesenteric resistance vessels, combined with depression of endothelium derived hyperpolarising factor mediated responses [61]. Furthermore, cerebral and intestinal resistance vessels suffused with high glucose in vivo showed impaired responses to ACh, linked to prostanoid mechanisms, ROS and stimulation of protein kinase $\mathrm{C}$ $[62,63]$. Like corpus cavernosum, responses of rat aorta were, however, unaltered by high glucose exposure [11], presumably because any modifications of prostanoid metabolism were minor and ACh relaxation is not mediated by endothelium derived hyperpolarising factor in these tissues.

In conclusion, diabetes has marked deleterious effects on corpus cavernosum relaxation in rats, similar to those found in human tissue. Thus, nitrergic NANC innervation and the endothelial NO system, which together can normally produced about $90 \%$ relaxation, have a joint diabetic deficit of about $40 \%$. Treatment with the antioxidant, LA, completely prevented corpus cavernosum dysfunction and substantially (50-65\%) corrected existing deficits. These data provide a rationale for the potential use of antioxidants in the treatment of diabetic impotence, as well as providing more general vascular benefits, which should be assessed in clinical trials.

Acknowledgements. This research was supported in part by grants from the British Diabetic Association, the British Heart Foundation and ASTA Medica AWD.

\section{References}

1. Saenz De Tejada I, Goldstein I, Azadzoi K, Krane RJ, Cohen RA (1989) Impaired neurogenic and endothelium-mediated relaxation of penile smooth muscle from diabetic men with impotence. N Engl J Med 320: 1025-1030

2. Azadzoi KM, Saenz De Tejada I (1992) Diabetes mellitus impairs neurogenic and endothelium-dependent relaxation of rabbit corpus cavernosum smooth muscle. J Urol 148: 1587-1591
3. Rehman J, Chenven E, Brink P et al. (1997) Diminished neurogenic but not pharmacological erections in the 2- to 3-month experimentally diabetic F-344 rat. Am J Physiol 272:H1960-H1971

4. Ignarro LJ, Bush PA, Buga GM, Wood KS, Fukoto JM, Rajfer J (1990) Nitric oxide and cyclic GMP formation upon electrical field stimulation cause relaxation of corpus cavernosum smooth muscle. Biochem Biophys Res Commun 170: 843-850

5. Burnett AL, Nelson RJ, Calvin DC et al. (1996) Nitric oxide-dependent penile erection in mice lacking neuronal nitric oxide synthase. Mol Med 2: 288-296

6. Vernet D, Cai L, Garban H et al. (1995) Reduction of penile nitric oxide synthase in diabetic BB/WORdp (type I) and BBZ/ WORdp (type II) rats with erectile dysfunction. Endocrinology 136: 5709-5717

7. Pieper GM, Gross GJ (1988) Oxygen free radicals abolish endothelium-dependent relaxation in diabetic rat aorta. Am J Physiol 257:H825-H833

8. Abiru T, Watanabe Y, Kamata K, Miyata N, Katsuya Y (1990) Decrease in endothelium-dependent relaxation and levels of cyclic nucleotides in aorta from rabbits with alloxan-induced diabetes. Res Commun Chem Pathol Pharmacol 68: 13-25

9. Keegan A, Walbank H, Cotter MA, Cameron NE (1995) Chronic vitamin $\mathrm{E}$ treatment prevents defective endothelium-dependent relaxation in diabetic rat aorta. Diabetologia 38: 1475-1478

10. Rösen P, Ballhausen T, Bloch W, Addicks K (1995) Endothelial relaxation is disturbed by oxidative stress in the diabetic rat heart: influence of tocopherol as antioxidant. Diabetologia 38: 1157-1168

11. Archibald V, Cotter MA, Keegan A, Cameron NE (1996) Contraction and relaxation of aortas from diabetic rats: effects of chronic anti-oxidant and aminoguanidine treatments. Naunyn Schmeidebergs Arch Pharmacol 353: 584-591

12. Pieper GM, Siebeneich, W (1996) Diabetes-induced endothelial dysfunction is prevented by long-term treatment with the modified iron chelator, hydroxyethyl starch conjugated-deferoxamine. J Cardiovasc Pharmacol 30: 734-738

13. Bucala R, Tracey KJ, Cerami A (1991) Advanced glycosylation products quench nitric oxide and mediate defective endothelium-dependent vasodilation in experimental diabetes. J Clin Invest 87: 432-438

14. Mayhan WG (1992) Impairment of endothelium-dependent dilation of the basilar artery during diabetes mellitus. Brain Res 580: 297-302

15. Hill MA, Ege EA (1994) Active and passive mechanical properties of isolated arterioles from STZ-induced diabetic rats: effect of aminoguanidine treatment. Diabetes 43: 1450-1456

16. Kihara M, Low PA (1995) Impaired vasoreactivity to nitric oxide in experimental diabetic neuropathy. Exp Neurol 132: 180-185

17. Maxfield EK, Cameron NE, Cotter MA (1997) Effect of diabetes on reactivity of sciatic vasa nervorum in rats. J Diabet Complications 11: 47-55

18. McVeigh GE, Brennan GM, Johnston GD et al. (1992) Impaired endothelium-dependent and independent vasodilation in patients with type 2 (non-insulin-dependent) diabetes mellitus. Diabetologia 35: 771-776

19. Johnstone MT, Creager SJ, Scales KM, Cusco JA, Lee BK, Creager MA (1993) Impaired endothelium-dependent vasodilation in patients with insulin-dependent diabetes mellitus. Circulation 88: 2510-2516

20. Nitenberg A, Valensi P, Sachs R, Dali M, Aptecar E, Attali JR (1993) Impairment of coronary vascular reserve and ACh-induced coronary vasodilation in diabetic patients with angiographically normal coronary arteries and normal left ventricular systolic function. Diabetes 42: 1017-1025

21. Morris SJ, Shore AC, Tooke JE (1995) Responses of the skin microcirculation to acetylcholine and sodium nitroprusside in patients with NIDDM. Diabetologia 38: 1337-1344

22. Wolff SP (1995) Diabetes mellitus and free radicals. Br Med Bull 49: 642-652

23. Gryglewski RJ, Palmer RMJ, Moncado S (1986) Superoxide anion is involved in the breakdown of endothelium-derived vascular relaxing factor. Nature 320: 454-456 
24. Palmer AM, Thomas CR, Gopaul N et al. (1998) Dietary antioxidant supplementation reduces lipid peroxidation but impairs vascular function in small mesenteric arteries of the streptozotocin rat. Diabetologia 41: 148-156

25. Packer L, Witt EH, Tritschler HJ (1995) Alpha-lipoic acid as a biological antioxidant. Free Rad Biol Med 19: 227-250

26. Nagamatsu M, Nickander KK, Schmelzer JD et al. (1995) Lipoic acid improves nerve blood flow, reduces oxidative stress and improves distal nerve conduction in experimental diabetic neuropathy. Diabetes Care 18: 1160-1167

27. Cameron NE, Cotter MA, Horrobin DH, Tritschler HJ (1998) Effects of $\alpha$-lipoic acid on neurovascular function in diabetic rats: interaction with essential fatty acids. Diabetologia 41: 390-399

28. Keegan A (1997) Mechanisms underlying defective aorta and corpus cavernosum function in experimental diabetes, [Thesis] University of Aberdeen, Aberdeen

29. Ralevic V, Belai A, Burnstock G (1995) Effects of streptozotocin-diabetes on sympathetic nerve, endothelial and smooth muscle function in the rat mesenteric arterial bed. Eur J Pharmacol 286: 193-199

30. Pelligrino DA, Albrecht RF (1991) Chronic hyperglycemic diabetes in the rat is associated with a selective impairment of cerebral vasodilatory responses. J Cereb Blood Flow Metab 11: 667-677

31. Taylor PD, Graves JE, Poston L (1995) Selective impairment of acetylcholine-mediated endothelium-dependent relaxation in isolated resistance arteries of the streptozotocin-induced diabetic rat. Clin Sci 88: 519-524

32. Cameron NE, Cotter MA (1992) Impaired contraction and relaxation in aorta from streptozotocin-diabetic rats: role of the polyol pathway. Diabetologia 35: 1011-1019

33. Sobrevia L, Cesare P, Yudilevich DL, Mann GE (1995) Diabetes-induced activation of system $\mathrm{y}^{+}$and nitric oxide synthase in human endothelial cells: association with membrane hyperpolarization. J Physiol 489: 183-192

34. Elabbady AA, Gagnon C, Hassouna MM, Begin LR, Elhilali MM (1995) Diabetes mellitus increases nitric oxide synthase in penises but not in major pelvic ganglia of rats. Br J Urol 76 : 196-202

35. Sullivan ME, Bell CRW, Dashwood MR et al. (1996) Autoradiographic localization of nitric oxide synthase binding-sites in normal and diabetic rat corpus cavernosum. Eur Urol 30: 506-511

36. Hirata K, Kuroda R, Sakoda T et al. (1995) Inhibition of endothelial nitric oxide synthase activity by protein kinase C. Hypertension 25: 180-185

37. Ohara Y, Sayegh HS, Yamin JJ, Harrison DG (1995) Regulation of endothelial constitutive nitric oxide synthase by protein kinase C. Hypertension 25: 415-420

38. Yagihashi S (1995) Pathology and pathogenetic mechanisms of diabetic neuropathy. Diabetes Metab Rev 11: 193-225

39. Cameron NE, Cotter MA (1996) Rapid reversal by aminoguanidine of the neurovascular effects of diabetes in rats: modulation by nitric oxide synthase inhibition. Metabolism 45: 1147-1152

40. Ishii H, Jirousek MR, Koya D et al. (1996) Amelioration of vascular dysfunctions in diabetic rats by an oral PKC $\beta$ inhibitor. Science 272: 728-731

41. Cameron NE, Cotter MA, Jack A, Hohman TC (1997) Inhibition of protein kinase $\mathrm{C}$ corrects nerve conduction and blood flow deficits in diabetic rats. Diabetologia 40 [Suppl 1] A31

42. Cameron NE, Cotter MA (1995) Neurovascular deficits in diabetic rats: potential contribution of autoxidation and free radicals examined using transition metal chelating agents. J Clin Invest 96: 1159-1163

43. Cotter MA, Love A, Watt MJ, Cameron NE, Dines KC (1995) Effects of natural free radical scavengers on peripheral nerve and neurovascular function in diabetic rats. Diabetologia 38 : $1285-1294$

44. Jack A, Cotter MA, Cameron NE (1998) Antioxidant treatment effects on defective endothelium-derived hyperpolarizing factor and relaxation in the mesenteric vasculature of diabetic rats. $\mathrm{Di}$ abetes 47 [Suppl 1] A54

45. Hattori Y, Kawasaki H, Kazuhiro A, Kanno M (1991) Superoxide dismutase recovers altered endothelium-dependent relaxation in diabetic rat aorta. Am J Physiol 261:H1086-H1094

46. Diederich D, Skopec J, Diedrich A, Dai F-X (1994) Endothelial dysfunction in mesenteric resistance arteries of diabetic rats: role of free radicals. Am J Physiol 266:H1153-H1161

47. Otter DJ, Chess-Williams R (1994) The effects of aldose reductase inhibition with ponalrestat on changes in vascular function in streptozotocin diabetic rats. Br J Pharmacol 113: 576-580

48. Beckman JS, Beckman TW, Chen J, Marshall PA, Freeman BA (1990) Apparent hydroxyl radical production by peroxynitrite: Implications for endothelial injury from nitric oxide and superoxide. Proc Natl Acad Sci USA 87: 1620-1624

49. Bierhaus A, Chevion S, Chevion M et al. (1997) Advanced glycation end product-induced activation of NF- $\kappa \mathrm{B}$ is suppressed by $\alpha$-lipoic acid in cultured endothelial cells. Diabetes 46: $1481-1490$

50. Whiteman M, Tritschler H, Halliwell B (1996) Protection against peroxynitrite-dependent tyrosine nitration and $\alpha_{1}$-antiproteinase activity by oxidized and reduced lipoic acid. FEBS Lett 379: 74-76

51. Way KJ, Reid JJ (1994) Nitric oxide-mediated neurotransmission is attenuated in the anococcygeus muscle from diabetic rats. Diabetologia 37: 232-237

52. Jenkinson KM, Reid JJ (1995) Effect of diabetes on relaxations to non-adrenergic, non-cholinergic nerve stimulation in longitudinal muscle of the rat gastric fundus. Br J Pharmacol 116: 1551-1556

53. Martinezcuestav MA, Massuda H, Whittle BJR, Moncada S (1995) Impairment of nitrergic-mediated relaxation of rat isolated duodenum by experimental diabetes. Br J Pharmacol 114: 919-924

54. Martin W, McAllister KHM, Paisley K (1994) NANC neurotransmission in the bovine retractor penis muscle is blocked by superoxide anion following inhibition of superoxide-dismutase with diethyldithiocarbamate. Neuropharmacol 33: 1293-1301

55. Ding YQ, Takada M, Kaneko T, Mizuno N (1995) Colocalization of vasoactive intestinal polypeptide and nitric oxide in penis-innervating neurons in the major pelvic ganglion of the rat. Neurosci Res 22: 129-131

56. Maher E, Bachoo M, Elabbady AA et al. (1996) Vasoactive intestinal peptide and impotence in experimental diabetes mellitus. Br J Urol 77: 271-278

57. Suh JK, Mun KH, Cho CK, Shin HC, Kim YS, Park TC (1995) Effect of vasoactive intestinal peptide and acetylcholine on penile erection in the rat in vivo. Int J Impotence Res 7: 111-118

58. Pickard RS, Powell PH, Zar MA (1993) Evidence against vasoactive intestinal polypeptide as the relaxant neurotransmitter in human cavernosal smooth muscle. Br J Pharmacol 108: 497-500

59. Tesfamariam B, Cohen RA (1992) Free radicals mediate endothelial cell dysfunction caused by raised glucose. Am J Physiol 263:H321-H326

60. Dorigo P, Fraccarollo D, Santostasi G, Maragno I (1997) Impairment of endothelium-dependent but not of endothelium-independent dilation in guinea-pig aorta rings incubated in the presence of raised glucose. Br J Pharmacol 121: 972-976

61. Taylor PD, Poston L (1994) The effect of hyperglycaemia on function of rat isolated mesenteric resistance artery. Br J Pharmacol 113: 801-808

62. Mayhan WG, Patel KP (1995) Acute effects of glucose on reactivity of cerebral microcirculation: role of activation of protein kinase C. Am J Physiol 269:H1297-H1302

63. Bohlen HG, Lash JM (1993) Topical hyperglycemia rapidly suppresses EDRF-mediated vasodilation of normal rat arterioles. Am J Physiol 265:H219-H225 